\title{
LOS CAMELLONES INDÍGENAS DE PAICAVÍ, ARAUCANÍA, CHILE, Y SUS IMPLICANCIAS SOCIO-ECONÓMICAS DURANTE EL PERIODO COLONIAL TEMPRANO: UN ENFOQUE PRELIMINAR
}

\author{
INDIGENOUS RAISED AGRICULTURAL FIELDS IN PAICAVÍ, LA ARAUCANÍA, \\ CHILE, AND THEIR SOCIO-ECONOMIC IMPLICATIONS DURING THE EARLY \\ COLONIAL PERIOD: A PRELIMINARY VIEW
}

Tom D. Dillehay ${ }^{1,2}$, José Manuel Zavala, ${ }^{3,4}$ José Saavedra y Arturo Rojas ${ }^{5}$

\begin{abstract}
Los campos agrícolas elevados (camellones) localizados en el delta del río Paicaví en la región de Araucanía, en el centro-sur de Chile, se describen y se consideran de manera preliminar en términos de sus implicancias sociales y económicas para el periodo Colonial Temprano. El material de archivo de los siglos XVI al XVII indica que esta área, que era parte de la provincia de Tucapel del denominado Estado de Arauco, posiblemente apoyó a los guerreros de Purén que resistieron con más fiereza a los españoles, proporcionando grandes cantidades de alimentos. El registro arqueológico de los campos elevados en el área apoya hipotéticamente este papel, al menos durante los tiempos de guerra entre los españoles y los mapuche.
\end{abstract}

Palabras claves: camellones, Colonial, mapuche, Araucanía, Purén, Tucapel.

Raised agricultural fields in the delta of the Paicaví River in the Araucanía region of south-central Chile are described and considered preliminarily in terms of their social and economic implications for the Early Colonial Period. Archival material of the 16th-17th centuries suggests that this area, which was part of the Tucapel province of the Araucanian Estado, possibly supported the warriors from Purén- who more fiercely resisted the Spanish--by providing large quantities of food. The archaeological record of the raised fields in the area hypothetically supports this role, at least during times of warfare between the Spanish and Mapuche.

Key words: Raised agricultural fields, Colonial, Araucanía, Purén, Tucapel.

La agricultura de campos elevados se practicaba en muchas partes del mundo. También existía en muchas partes de América donde el drenaje natural era insuficiente o cuando las estaciones húmedas cortas pero intensas eran seguidas por largas estaciones secas con cantidades de agua insuficientes para mantener la producción al nivel requerido. Generalmente estos campos se ubicaban en zonas de humedales y consistían en cavar canales de drenaje en franjas a lo largo del suelo, acumulando la tierra en los costados para formar crestas o columnas sobre elevadas sobre las cuales sembraron y cultivaron las plantas. La noción de campos elevados, o camellones, incluye la preparación del terreno para su nivelación, la transferencia de materiales terrosos para elevar el nivel del suelo natural (p.ej., ondulaciones, plataformas y montículos artificiales) con el fin de mejorar las condiciones de cultivo, especialmente cuando existe un drenaje deficiente del suelo o hay disponibilidad de humedales posibles de modificar y sembrar. En las Américas, la mayoría de tales campos son de origen pre-europeo y fueron abandonados hace mucho tiempo, excepto por unas pocas chinampas aún cultivadas en México (Denevan 1980), los campos elevados o waruwaru en el altiplano peruano (Erickson 1983, 1984, 1985, 1986a, 1986b, 1986c, 1986d, 1987, 1988a, 1988b, 1992, 1996; Garaycochea 1982, 1984, 1986a, 1986b, 1986c,

\footnotetext{
${ }^{1}$ Department of Anthropology, Vanderbilt University, Nashville, EEUU. tom.d.dillehay@ vanderbilt.edu

${ }^{2}$ Escuela de Arqueología, Universidad Austral de Chile, Puerto Montt, Chile.

${ }^{3}$ Departamento de Ciencias Históricas, Universidad de Chile, Santiago, Chile. josezavala@uchile.cl

${ }^{4}$ Instituto de Estudios del Hábitat, Universidad Autónoma de Chile, Temuco, Chile. josedeltsaavedrazapata@gmail.com

${ }^{5}$ Stradale, Ingeniería de Proyectos y Asesorías Ltda., Temuco, Chile. arturorojas1954@gmail.com
} 
1987a,1987b) y, hasta recientemente, los camellones actuales de los mapuche en el Valle de Purén en el centro-sur de Chile (Dillehay 2017).

Desde el punto de vista socio-cultural, existen casos pre-europeos en las Américas muy sólidos respecto a que su construcción, mantenimiento y gestión fueron el resultado de la coordinación entre grupos locales de agricultores y/o el producto de la planificación en el marco de una sociedad compleja (p.ej., Denevan 2001:220). Por ejemplo, en varios valles de la vertiente occidental andina de Ecuador y Perú y en el altiplano de Bolivia, cerca del Lago Titicaca, los agricultores pre-hispánicos construyeron camellones (Erickson 1995). También, se encuentran campos elevados en las tierras bajas de Colombia y Guyana (Iriarte et al. 2010). En todas estas regiones, los campos de camellones fueron obras de Estados imperiales (casos de Perú y Bolivia) o bien de jefaturas (casos de América Central, Colombia y Guyana). Hasta ahora, no hay evidencias de camellones en los valles septentrionales y centrales de Chile y no sabemos si los que hemos identificados en el centro-sur de Chile fueron producto de un desarrollo local autónomo. Con todo, ya hemos postulado en una publicación anterior la probabilidad de que la tecnología de los camellones de La Araucanía no fuera un desarrollo independiente, sino que posiblemente viniera de la zona de Tiawanaku o de la costa peruana (Dillehay et al. 2012).

Más especificamente, la presencia de los campos elevados ha sido documentada en varias regiones del Centro y Sur de América: México (Siemens 1989), Colombia (Broadbent 1968; Parsons 1966; Plazas y Falchetti 1981), Ecuador (Bouchard y Usselmann 2003; Parsons 1969), Perú (Pozorski et al. 1983), Bolivia (Denevan 1963, 2001; Erickson 1995; Kolata 2003), Venezuela (Gassón y Rey 2006; Zucchi y Denevan 1979) y las Guayanas (Iriarte et al. 2010; Rostain 2008). Todos ellos incumben tierras agrícolas en las llanuras aluviales que mitigan los altos niveles de agua en las llanuras inundables, controlan el drenaje, enriquecen el suelo con nutrientes frescos e influyen en el microclima, especialmente en la humedad. Uno de los sistemas hidráulicos más extenso de campos elevados en toda América está ubicado en la llanuras bajas del Río San Jorge del Caribe colombiano (Parsons 1966; Plazas y Falchetti 1981). Una extensa investigación arqueológica de este complejo ha asignado los comienzos de la transformación del paisaje y la primera ocupación humana densa entre 2000 y 1000 años radiocarbónicos AP (sin calibrar) (Groot 1992).

El estudio que presentamos aquí corresponde a resultados preliminares obtenidos de un conjunto creciente de datos e interpretaciones empíricas sobre la distribución espacial y temporal, las características físicas y las funciones de la agricultura de campos elevados artificiales de la Araucanía histórica, en ciertos lugares de la costa del Pacífico en las Regiones VIII (Biobío) y IX (La Araucanía) de Chile y particularmente, en este caso, del área del río Paicaví (Comuna de Cañete, Provincia de Arauco, Región de Biobío; Figura 1). Los datos han sido generados desde 2001 por varios proyectos preliminares interdisciplinarios arqueológicos y etnohistóricos (Dillehay 2007; 2017; Dillehay y Saavedra 2003; Dillehay y Zavala 2013; Dillehay et al. 2007; Zavala y Dillehay 2010; Zavala et al. 2018). Los datos más recientes derivan de una investigación en curso a lo largo del litoral costero entre Arauco y Tirúa y se han sumado a nuestra perspectiva anterior, particularmente con respecto a los orígenes y organización prehispánica tardía de la agricultura de campos elevados en el delta del Río Paicaví, ubicado aproximadamente a $20 \mathrm{~km}$ al suroeste de Cañete (Dillehay et al. 2007).

Nuestro enfoque para las investigaciones sistemáticas en espacio y tiempo de la agricultura de campos elevados se enmarca en términos de un modelo general de distribución que consiste en las siguientes proposiciones: (1) la evidencia actual sugiere que la agricultura de campo elevado probablemente se inició en los humedales de los estuarios costeros de La Araucanía 1200-1300 DC (Dillehay 2017; Dillehay et al. 2007); (2) en el periodo Colonial desde 1550 a 1800 DC, la agricultura de campo elevada probablemente se integró en un sistema de producción intensiva de alimentos en apoyo intermitente a la resistencia armada de poblaciones mapuche a la invasión española al sur del Río Biobío (Dillehay 2017); y, también pudo haber sido aprovechada por los españoles durante sus avanzadas en territorio mapuche gracias a pactos y alianzas con los grupos productores o simplemente a través de su subyugación; (3) la agricultura de campo elevado probablemente disminuyó durante el proceso de ocupación chilena que se incrementa paulatinamente a partir de mediados del siglo XIX en las planicies costeras hasta consolidarse en la década de 1880 . Hoy no existe una memoria social clara de esta práctica en el área costera; es una estrategia agrícola que en gran parte se ha perdido debido a la modernización y desaparición gradual de los modos de vida indígena tradicionales. Sin embargo, en el Valle de Purén, en la vertiente oriental de la cordillera Nahualbuta, se sigue practicando esta forma de agricultura (Dillehay et al. 2012) (Figura 2).

Nuestros recorridos arqueológicos, testeos de sondaje y análisis de la distribución de campos elevados inmediatamente al sur de la desembocadura del Río Paicaví, se han realizado entre 2010 y 2017. Como señalamos antes, tales estudios se enmarcan en varios proyectos más amplios, los primeros enfocados en el Valle de Purén-Lumaco (Dillehay 2007, 2017; Dillehay y Saavedra 2010), posteriormente en relación a los 


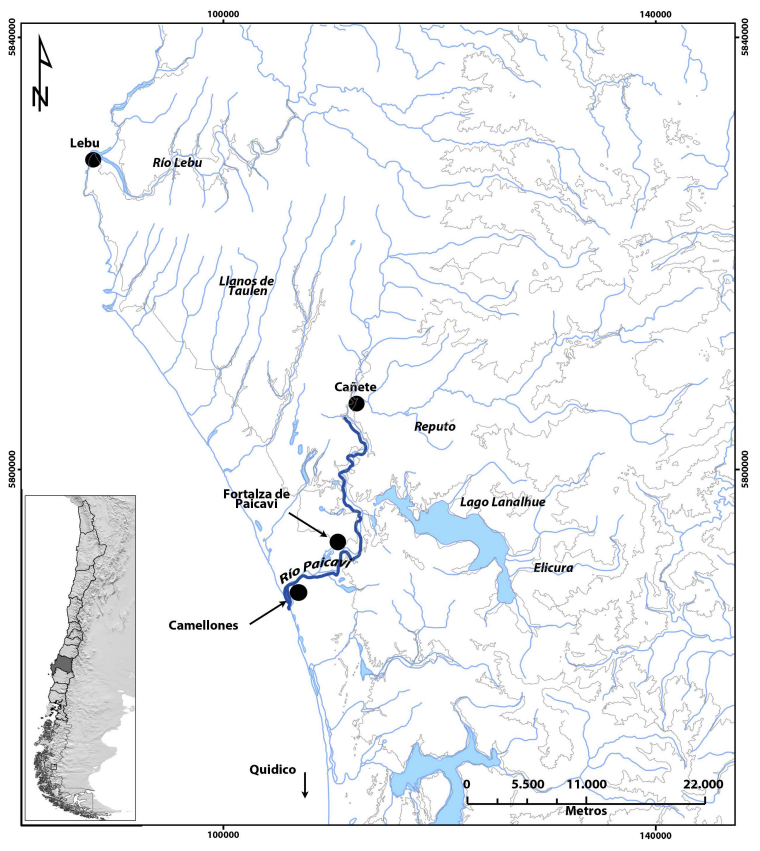

Figura 1. Ubicación del área de estudio.

Location of study área.

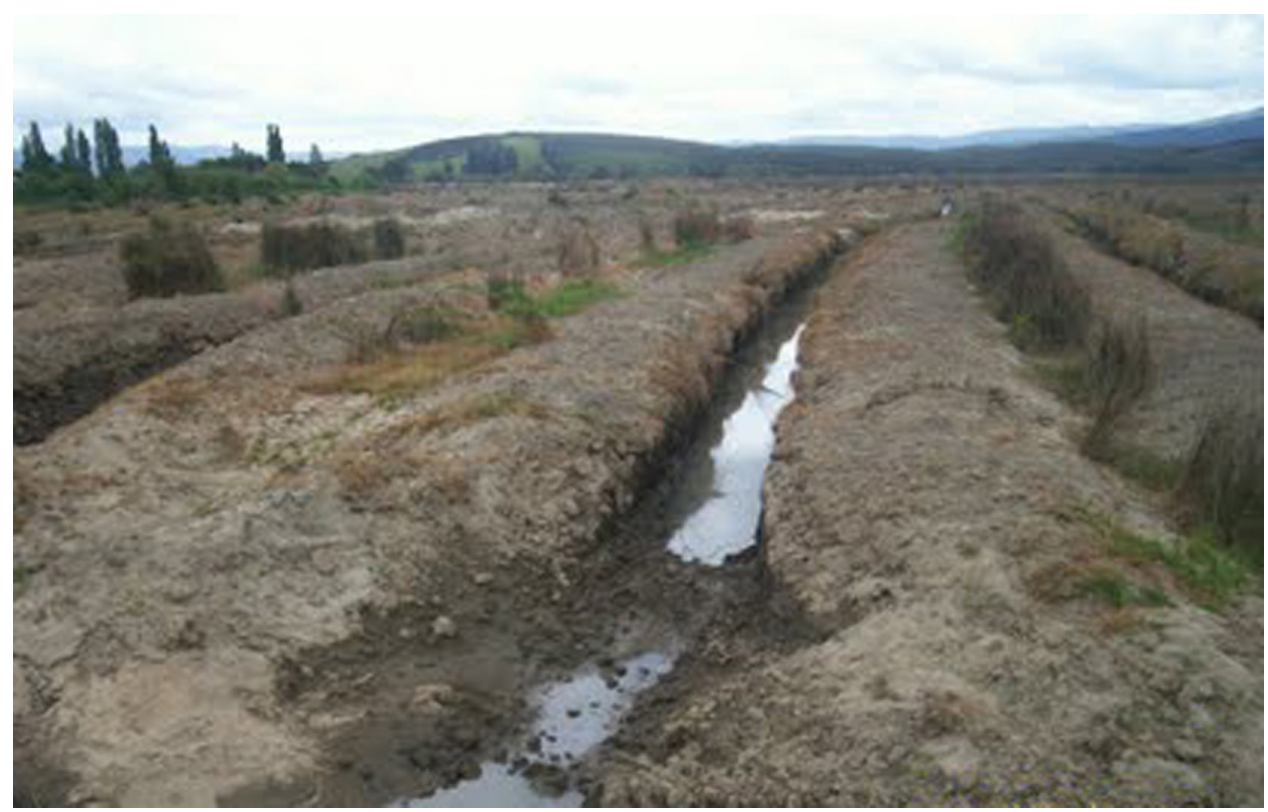

Figura 2. Estos camellones se usaban a fines del siglo XX para cultivar papas en el suelo de los valles de Purén y Lumaco. No se sabe cuando fueron construidos.

These camellones were used at the end of the 20th century to cultivate potatos in the Purén and Lumaco Valley. Not known is when they were first built. 
Parlamentos Mapuche-Españoles (Zavala 2015; Zavala et al. 2015) y, últimamente respecto a lavaderos de oro del siglo XVI en La Araucanía (Zavala et al. 2018). Previamente, habíamos estudiado campos elevados en las áreas del Lago Budi y Puerto Saavedra (Dillehay 2007, 2017; Dillehay et al. 2007). Para estas áreas se estima que su construcción se inicia ca. 1300 DC. Esto, basados en una fecha de radiocarbono tomada en una sección bajo la superficie del campo elevado y en correlato al análisis de fragmentos cerámicos diagnósticos asociados directamente con los camellones (Dillehay et al. 2007). Igualmente, se ha descubierto que los mapuche del Lago Budi llamaron a la forma de estos campos elevados: deume, lo que significa en idioma mapudungun "grandes construcciones u obras"1.

Posterior al estudio en el sector costero del Lago Budi y Puerto Saavedra, nuestra investigación de los sistemas de campos elevados se extendió hacia el norte incluyendo la zona costera comprendida entre Arauco y Tirúa pudiendo excavar y fechar antiguos campos agrícolas en el área de Paicaví.

En síntesis, este artículo describe los resultados preliminares del estudio arqueológico realizado en dicha zona por Tom Dillehay y José Saavedra y correlatos etnográficos de Arturo Rojas, incluyendo referencias a un estudio de fuentes históricas de la zona realizado por el etnohistoriador José Manuel Zavala.

\section{Fuentes Históricas sobre Paicaví}

Las fuentes consultadas provienen principalmente del Archivo General de Indias de Sevilla (AGI) y del Archivo Nacional Histórico de Santiago de Chile (ANHCh). Mención especial cabe hacer de la búsqueda que se hizo de las exploraciones hidrográficas y costeras del siglo XIX, lo que nos llevó al estudio de material histórico del Ministerio de Marina de Chile y a la localización de la cartografía de dicha época. Por otra parte, se realizó una revisión de los cronistas de los siglos XVI y XVII y de la reciente producción histórica sobre el área.

Para ubicar el área de investigación en un contexto histórico, durante la segunda mitad del siglo XVI y luego de ser sometidas al dominio español, las poblaciones mapuche del sur del Río Biobío comenzaron a resistir con éxito a dicho dominio, particularmente en torno a la Cordillera de Nahuelbuta, en el corazón del denominado Estado de Arauco, que considera una alianza de cuatro grandes conglomerados político-territoriales: Arauco, Catiray, Tucapel y Purén (Figura 3). En su avance hacia la solidaridad política, el también denominado "Estado indómito" mantuvo una estructura de autoridad descentralizada aunque coordinada
(Bengoa 2003; Dillehay 2007; Zavala 2008). Algunos datos históricos, aunque no son concluyentes, tienden a sugerir que durante periodos de conflicto, aquellas agrupaciones que no entraban directamente en enfrentamiento con los españoles asumían responsabilidades diferentes pero complementarias con el fin de auxiliar a los combatientes, como por ejemplo producir alimentos, proporcionar refugio, servir de intermediarios para negociaciones de paz, etc. (Bengoa 2003; Dillehay 2007; García de Loyola 1598; Góngora Marmolejo 1862 [1575]; Mariño de Lobera 1960 [1580]; Olaverría 1852 [1594]; de Valdivia 1955 [1555]; Vivar 1966 [1555]; Rosales 1878; Zavala 2008, 2015; Zavala y Dillehay 2010). Es así como la "provincia" de Tucapel -de la cual el territorio de Paicaví era uno de sus principales componentes-, es señalada en la documentación de la segunda mitad del siglo XVI y principios del siglo XVII ejerciendo un rol de apoyo o reforzamiento a la "provincia" de Purén ya sea proporcionando alimentos o bien refuerzos militares.

El estudio arqueológico preliminar de Paicaví puede sugerir este mismo papel, como se deduce de la presencia de grandes montículos artificiales (kuel), extensos campos agrícolas elevados, sitios domésticos y posiblemente pozos de almacenamiento de alimentos (Dillehay 2014).

Hasta ahora, hemos investigado extensamente y publicado sobre la etnohistoria y la arqueología de Purén y el papel defensivo principal que jugó en la guerra (Dillehay 1990, 2003, 2007, 2010; Dillehay y Saavedra 2003; Zavala y Dillehay 2010). Las indagaciones históricas indican que los dominios o provincias del denominado Estado, en particular las de Arauco y Tucapel, se asignaron una combinación de funciones defensivas, logísticas, de apoyo y de elaboración de tratados. Por ejemplo, en 1602 Alonso de Sotomayor revelaba los roles especializados de las provincias observando el compromiso español de destruir las cosechas de Tucapel y Arauco debido al apoyo que entregaban a los guerreros de Purén.

... para apurar y rendir aquella provincia de puren mas presto no a de comensar por ella que será muy difícil y trabajosa y las causas desto están bien entendidas de los hombres prácticos de aquella tierra y así tome el principio por las de arauco y tucapel que quitaba el socorro y calor que estas le dan ella después por si sola no podrá sustentarse (Alonso de Sotomayor, 1602, ANHCh, MVM, vol. 272, f. 158).

En 1598, García de Loyola ya había señalado las relaciones complementarias entre las diferentes partes 


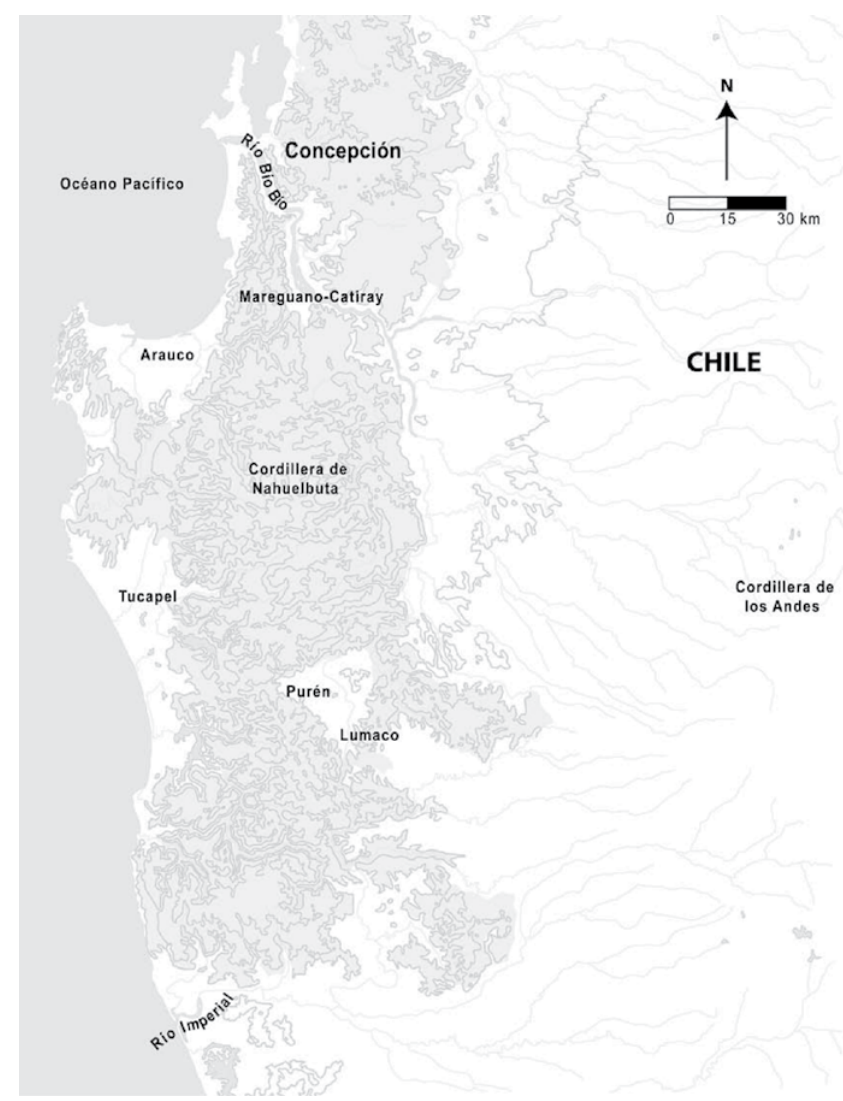

Figura 3. Las cuatro provincias del Estado de Arauco.

The four provinces of the Estado of Arauco.

del Estado, sus actos de resistencia y la especialización de Tucapel en la producción de alimentos y de Purén en la defensa militar: " $[\ldots]$ era notorio la ayuda que daban [los Tucapeles] á los purenes y que les hazían sus sementeras en el estado de tucapel" (García de Loyola al Rey, 17/01/1598, ANHCh, MVM, vol 273, f.67).

Bengoa (2003) igualmente describe el papel militar de las poblaciones en Purén, que fueron apoyadas logística y económicamente por la población vecina de Tucapel.

Así como había patrullas de conquistadores [españoles] que asolaban el territorio, comenzaron a haber grupos de indios que dedicaron toda su energía a combatir, emboscar, atacar y hacer daño al enemigo... el primer y más importante grupo que dio lugar a este nuevo "ejército de la frontera", fueron los de Purén... cuya fama como guerreros se manifiesta a lo largo de la historia... En resumen, vemos una sociedad indígena extendida a lo largo de una frontera, defendida por grupos, tales como los Puréninos, que estuvieron permanentemente en armas en una zona interior [por ejemplo, Tucapel]... que los apoyaron... (Bengoa 2003:423).

Todavía no se conocen los detalles organizativos y administrativos de cómo y por qué habitantes de la "provincia" de Tucapel, a la cual pertenecía Paicaví, se especializaron en proporcionar sustento a la "provincia" de Purén, y de todas las manifestaciones arqueológicas que reflejan este rol de apoyo especializado dentro del sistemapolítico.Aúnnotenemos certezasilos camellones agrícolas de Paicaví fueron una parte significativa de este sistema de solidaridad transcordillerana de Nahuelbuta observada en los primeros tiempos de la ocupación española. Tampoco hemos podido determinar si esta especialización y roles particulares y complementarios de los dominios o provincias nahuelbutanas fueron continuos y prolongados en el tiempo o solo operaron en ciertas coyunturas. La evidencia arqueológica, como veremos más adelante, parece inclinar inicialmente la balanza hacia una intermitencia en estas funciones, considerando que los pisos excavados en los camellones de Paicaví reflejan mas una utilización de renovación intermitente y no muy intensiva, sugiriendo su 
funcionamiento en momentos especiales en que se requería una mayor producción, ya sea para apoyar otros grupos que no podían cultivar sus tierras por encontrase en conflicto o bien por un aumento temporal de la demografía generado por la presencia de las fuerzas españolas y sus aliados indígenas.

\section{Paicaví y el denominado "Estado de Arauco" en el siglo XVI}

Las primeras referencias explícitas a Paicaví surgen a propósito de la muerte de Pedro de Valdivia en diciembre de 1553. El Canto II de la famosa Araucana de Alonso de Ercilla y Zúñiga inmortalizó la asamblea donde se habrían reunido los diversos territorios de las provincias de Tucapel y Arauco para elegir al Toqui que dirigiría el alzamiento, luego de la muerte de Valdivia.

Hicieron esta junta en el pueblo de Tocapel, y allí hicieron grandes convites $\mathrm{y}$, pareciéndoles que era necesario de nombrar un señor a quien obedeciese y les mandase en las cosas de la guerra de los españoles y, juntos estos señores, les pareció bien. Se levantaron Colocolo, que era señor de 6 mil indios, y Paylaguala, que era señor de 5 mil indios, y Paicaví, señor de 3 mil indios. Illacura señor de más de 3 mil indios y Tocapel, señor de más de 3 mil 500 y Teopolican, señor de cuatro mil indios, Ayllacura, señor de más de 5 mil indios (Ercilla 1575:29-32).

En 1604, luego de la gran rebelión (1598-1602) que había hecho replegar a los españoles al norte del Río Biobío, el gobernador Alonso de Rivera emprende una gran ofensiva a las "provincias" de Arauco y Tucapel, forzando el apoyo de los caciques de Arauco, quienes le habrían proporcionado 500 lanzas (Rosales 1878, t. 2, p. 421), se dirige al sur y establece un fuerte en Lebu, a una legua del mar, que bautiza con el nombre de Santa Margarita de Austria. Desde allí campea los diversos territorios de Tucapel talando los campos, incendiando las casas y capturando prisioneros, de modo que dichos territorios se ven obligados a solicitar la paz, para lo cual Rivera dispone un parlamento con todos los representantes de Arauco y Tucapel en Paicaví el 24 de enero de 1605 (Rosales 1878, t. 2, pp. 422-424), luego de lo cual establece la edificación de un fuerte en la ribera de dicho río (Santa Inés de Monterrey).

El fuerte español de Paicaví, fundado en 1605 , subsistió, al parecer hasta 1612, para luego ser refundado dos veces más a lo largo del siglo XVII en un lugar diferente, abriendo así algunos periodos de presencia española, cuya intensidad parece no haber sido demasiado marcada por lo escaso de la información documental al respecto; esos periodos van desde 1641 a 1646 y desde 1668 hasta fines del siglo XVII. Las evidencias físicas de la existencia de dos emplazamientos defensivos españoles en la ribera del Río Paicaví nos la proporciona un mapa de 1874, hecho a partir de los levantamientos cartográficos de Fitzroy (1835) y de la marina chilena (1867-70) y donde figuran las ruinas de dos fuertes (South America West Coast, Sheet v, Chile, Cape San Antonio To Tucapel Point). Concordante con este indicador cartográfico, es el relato de Oscar Viel quien exploró por tierra el Río Paicaví justamente con el fin de proporcionar información para la elaboración de la cartografía de la marina chilena incorporada en el mapa de Fitzroy, y dice al respecto:

El Rio Paycaví como he dicho a V. S. es formado por la confluencia del Peleco i del desaguie de Lanalhue i tiene solo una estención de dos leguas a lo más. Este río por el contrario de todos los que siegan el llano de Taulen es encajonado i corre en medio de dos altos barrancos que solo permiten atravesarlo en dos partes, en el vado frente al cual está el fuerte levantado por los Españoles i donde se hecha en el mar, parte cenagosa i sus riveras encombradas de arenas movedisas. En la corta estención que tiene este río, es bastante profundo por que está mui acanalado i suceptible de ser navegado por embarcaciones, pero al hecharse al mar, su boca se estiende i [solo habrá] un hilo de agua incapaz de soportar embarcación alguna, aun que no tuviera el grandísimo inconveniente de lo mui bravo que es el mar en ese lugar (ANHCh, MM, vol. 145, "Estados Jenerales del Vapor "Maule", 1857 a 1866 y 1867, fsj. [3v-4]).

Ignacio Domeyko, quien recorre Arauco y Tucapel en febrero de 1845 , señala a propósito del territorio situado entre Cañete y Paicaví:

Partiendo de Tucapel Viejo, el camino se arrima a la costa i casi desde el pié de la mencionada meseta i de unos cerros de pizarra que se hallan como a tres o cuatro leguas de la playa, principia la famosa pampa de Taulen, cuyos potreros cubiertos de pasto alto i tupido bajan hasta la orilla de la mar, ocupando casi todo el espacio entre los rios Leubú i Paycaví. Este llano bajo i pastoso se une por el rio Paicaví con el de Licureo, i al mismo tiempo se prolonga, aunque menos fértil i ménos ancho, por toda la playa hasta el rio Cudico (Domeyko 1846:26).

Algunos años después, en 1852, el vice-prefecto de misiones, Fray Diego de Chuffa señalaba un 
panorama similar al descrito por Domeyko en su memoria de misiones:

Se halla situada [la misión de Tucapel] a las 55 leguas mas o menos sudoeste de Concepción: a distancia de ocho leguas al sur de la misión, en un paraje llamado Paicaví se encuentran reunidos a corta distancia ciento y mas poblaciones de indios atraídos por la amenidad del lugar, fertilidad del terreno y su vasta llanura, que la riega y casi la roda un remanso y copioso río... (Chuffa 2007:125-126).

En resumen, el valor de estas citas -que sabemos son tardías pero que corresponden a las primeras observaciones chilenas de un territorio que se había mantenido bajo dominio indígena durante siglos- es la concordancia entre varios observadores respecto del espesor demográfico que evidencia la existencia de recursos, la fertilidad de los suelos y la extensa producción agrícola asociada con el área situada entre los ríos Lebu y Paicaví.

\section{¿Camellones o Dunas Naturales?}

A pesarde las constantes referencias alaabundanciade cultivos en las planicies costeras de Arauco y Tucapel, poco o nada se señala sobre las técnicas agrícolas. Domeyko se refiere al uso del fuego para rozar los pastizales al norte del Río Paicaví (llano del Taulen), lo que observó en su viaje de 1845. Vidal Gormaz (ANHCh, MM, vol. 145, F., pp. 3-4) describe, en su exploración de 1862, las huellas de los imponentes surcos que, a distancia de un metro y medio unos de otros, descendían de las colinas próximas al río Lebu (ANHCh, MM, vol.145, F., p. 3-4). Ninguna mención explícita a terrazas agrícolas o del tipo camellones hemos encontrado en la documentación revisada. Dicho lo anterior, en el mapa de Fitzroy aparecen muy nítidamente dibujadas unas prominencias circulares que se extienden a lo largo de la costa al sur del Río Paicaví, el autor las designa como dunas de arena ("sand hills"; Figura 4). ¿Podría tratarse de montículos artificiales o camellones? Cabe destacar que los camellones que hemos detectado arqueológicamente en Paicaví, se ubican exactamente donde Fitzroy ha marcado los "sand hills".

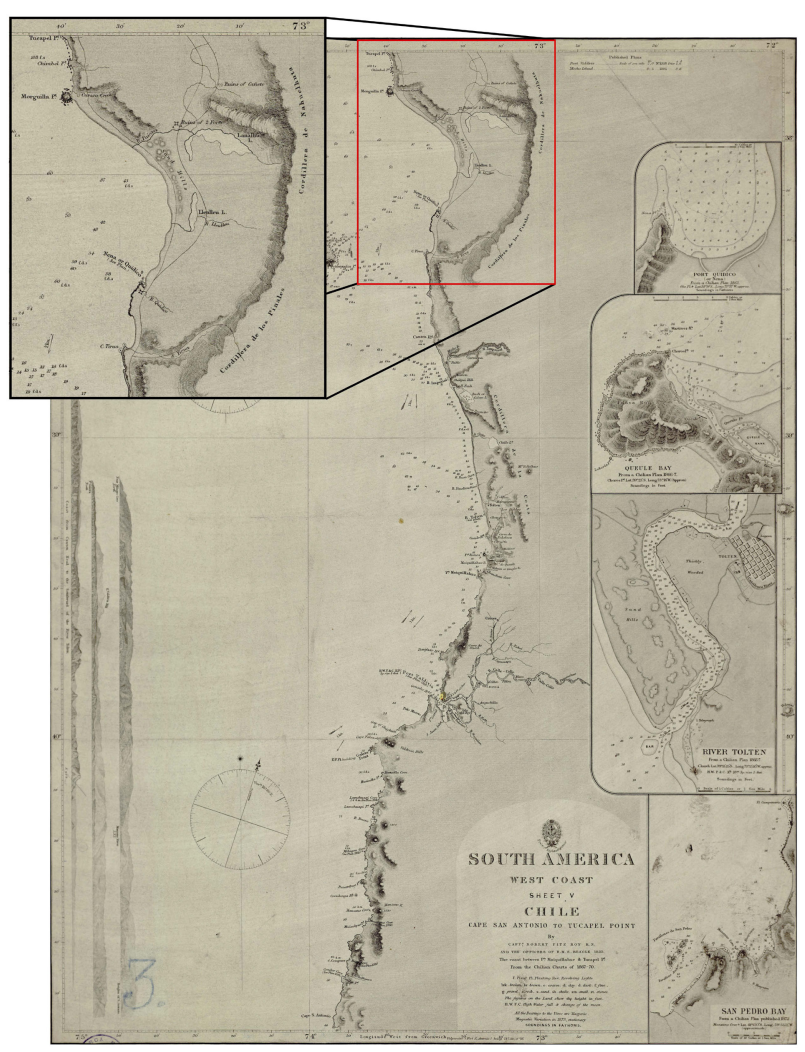

Figura 4. Mapa de Fitzroy de la costa sur-centro pacífica entre el cabo de San Antonio y Tucapel, Chile.

Map of Fitzroy showing the south-central Pacific coast beetween Cabo de San Antonio and Tucapel, Chile. 
Por otra parte, la gran distancia entre surcos mencionados en las montañas vecinas al Río Lebu sugiere que estos no son campos agrícolas ordinarios donde los surcos generalmente están separados en una distancia de 30 a $50 \mathrm{~cm}$, en lugar de los 1,0 a 1,5 m señalados. Lo más probable es que este tipo de separación espacial más extensa represente campos elevados pequeños como los que se ven hoy en día en el Valle de Purén (Figura 2). Aunque la figura muestra campos largos y elevados separados por aproximadamente $0,5 \mathrm{~m}$, otros en la misma área son ligeramente más altos con espacios de por lo menos 1,0 m entre ellos (Dillehay 2014), lo cual se condice mejor con lo descrito arriba para el área del Río Lebu.

Además, hoy en día no hay dunas de arena o sand hills en la zona exacta donde se encuentran los camellones al sur del Río Paicaví (Figura 5). Las empresas forestales modernas no han logrado establecer plantaciones de pinos en los camellones (Empresa Cambium, com. pers. 2015), pero los han cultivado inmediatamente fuera de los camellones, lo que sugiere que la modificación a largo plazo del sedimento de los camellones inhibe el crecimiento de las plantas de pino, a diferencia de las áreas adyacentes no modificadas.

En resumen, no hay duda de que las ricas tierras fértiles del Río Paicaví y otros lugares en el área proporcionaron alimentos agrícolas sustanciales para los mapuche y españoles, como las gramíneas. Además de esto, creemos que los campos elevados que hemos registrado al sur del delta del Río Paicaví se incorporaron significativamente a la producción de alimentos de cultivo en el área, probablemente durante la segunda mitad del siglo XVI siendo posiblemente usados, aunque de manera intermitente, hasta fines del siglo XVII. Claramente, como se describe en la documentación histórica, Paicaví y las áreas vecinas de Tucapel y Arauco, contaban con fuerza de trabajo lo suficientemente numerosa para laborar y mantener las tierras agrícolas de campos elevados en ciertos periodos a lo largo de la costa y en otras tierras agrícolas en el interior. A mediados del siglo XVI, Vivar y Ercilla dan cifras similares acerca de la población estimada de Arauco y Tucapel: 35.500 Vivar (1966 [1558]:173-174) y 27.000 Ercilla (1575 [1569]:29-32).

La presencia española en el corazón de la "provincia" de Tucapel durante el siglo XVI con la ciudad de Cañete (1557-1598) y, posteriormente, una vez desaparecida dicha ciudad, la existencia intermitente de un fuerte y de una misión en las proximidades de la antigua ciudad y, más aún, las episódicas vidas de un fortín española en el lado norte del Río Paicaví durante el siglo XVII, podría significar que estos campos elevados agrícolas están proveyendo de alimentación, tanto a los españoles como a la población indígena obligada a trabajar en los lavaderos de oro en la cercana cordillera de Nahuelbuta. Por otra parte, durante el siglo XVII y principalmente a lo largo del siglo XVIII, la guerra entre los mapuche y los españoles se limitó a periodos cortos y probablemente no fue necesario recurrir a los campos elevados costeros para aprovisionar de alimentos de manera extraordinaria a una fuerza combatiente.

Por otra parte, no sabemos si Fitzroy cuando menciona sand hills se refiere a dunas de arena

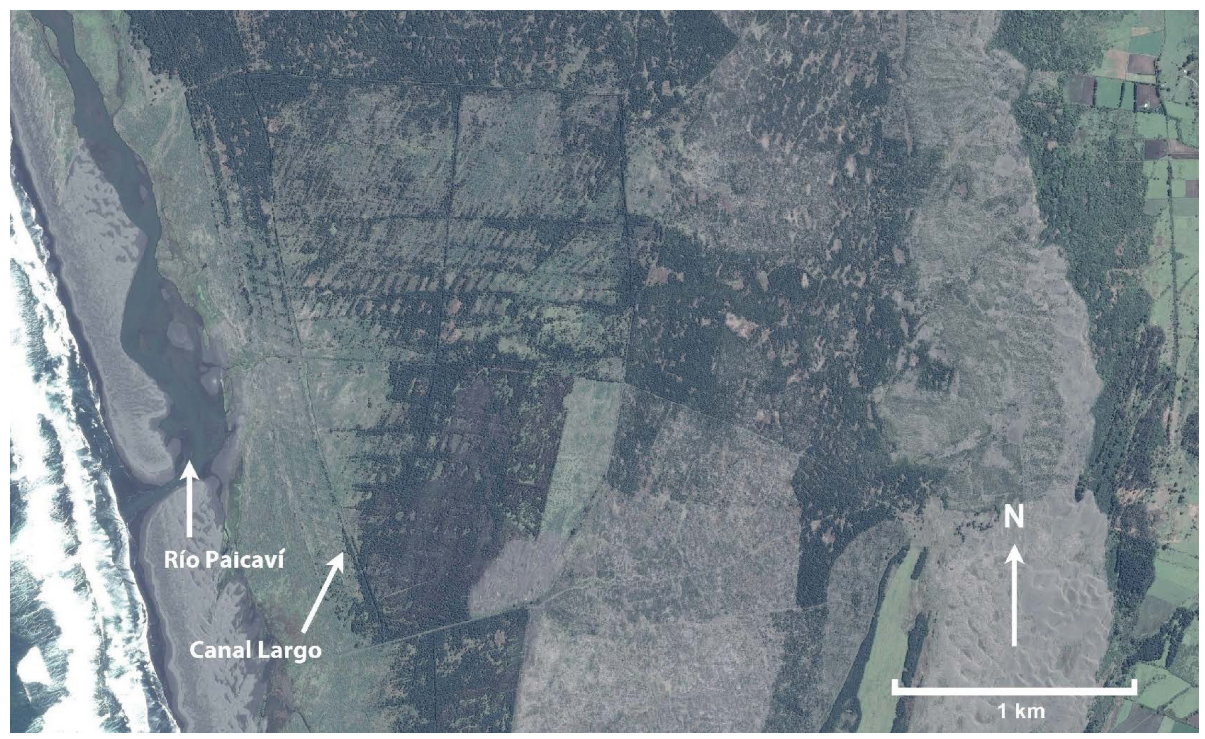

Figura 5. Vista aérea de los camellones arqueológicos al sur del delta del Río Paicaví.

Aerial view of the archaeological raised fields south of the Paicavi River delta. 
naturales o a camellones artificiales cuando menciona sand hills. ¿Y por qué los llama así, siendo más correcto en inglés esta última denominación para referirse a dunas naturales? Curiosamente, también existen extensos campos de dunas naturales a lo largo de la costa, especialmente desde Lebu por el norte hasta Quidico por el sur (Figura 1), pero el autor del mapa solo se refiere a estas sand hills de Paicaví y las coloca justo al sur del delta del Río Paicaví. Si las hubiera considerado dunas naturales, probablemente las habría denominado como tales (sand dunes) y las habría dibujado a lo largo de toda la costa en su mapa. ¿Destaca las sand hills porque no sabía lo qué eran, pero quería distinguirlas de las dunas naturales de arena denominándolas así? Los exploradores e ingenieros ingleses usualmente eran muy precisos en su terminología, por lo que es muy posible que lo que Fitzroy en realidad observó y calificó como sand hills fueran los camellones que señalamos aquí.

\section{Los campos agrícolas elevados en Paicaví}

La cuenca del drenaje Paicaví contiene la mayor extensión de campos elevados $\left(\sim 2,1 \mathrm{~km}^{2}\right)$ y con una clara expresión en superficie descubiertos a lo largo de la costa de la Araucanía (Figuras 5-7). Nuestro estudio preliminar del área se basa en la inspección del terreno, el análisis de fotografías aéreas y pruebas limitadas en perfiles expuestos del subsuelo. Los campos ocupan una planicie litoral costera, ancha y arenosa suave, ubicada inmediatamente al interior de la línea de playa, al sur de la desembocadura del Río Paicaví.

Como se mencionó anteriormente, además de los campos de Paicaví, existen otros campos elevados en la costa de la Araucanía, cercanos a la localidad de Puerto Saavedra, al sur de la desembocadura del Lago Budi.

La explicación de esta esporádica distribución en puntos específicos del litoral costero no es inmediatamente obvia, aunque es probable que esté relacionada con los drenajes interiores de ríos y lagos hacia el mar y presencia de estuarios o humedales costeros.

En el área de Paicaví, las modificaciones hidráulicas artificiales fueron aparentemente diseñadas para facilitar la recuperación de un humedal o estuario natural para la producción agrícola. A diferencia de los campos elevados en las áreas del Lago Budi y Puerto Saavedra, que han

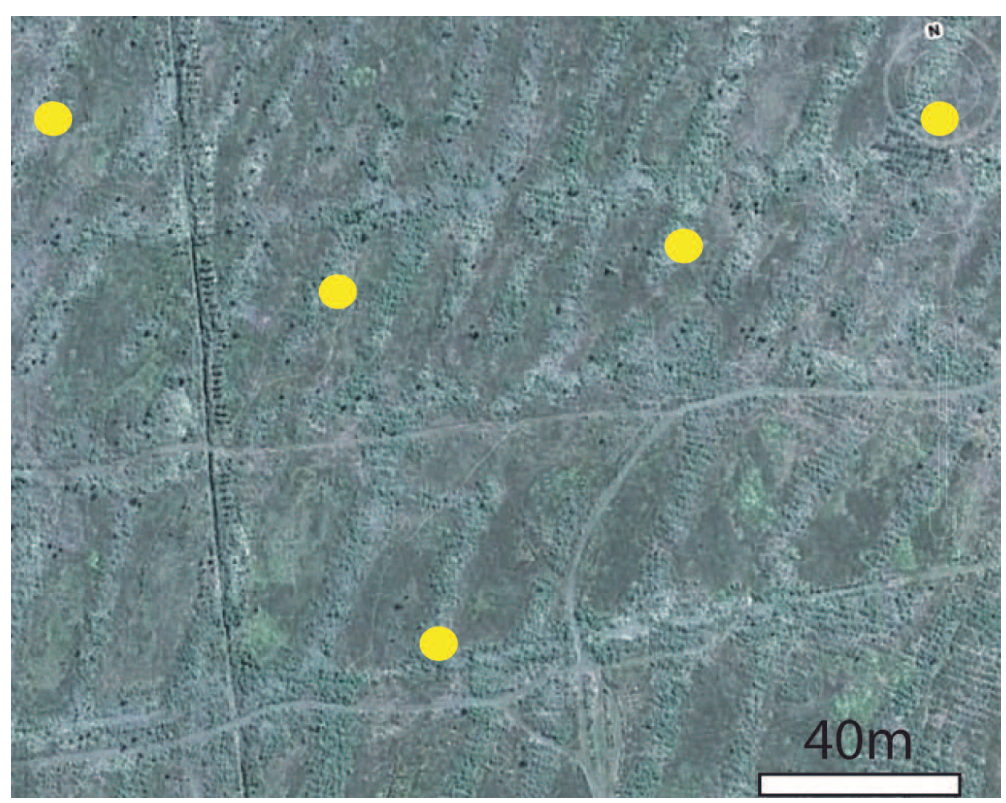

Figura 6. Vista aérea mas cercana de los camellones de Paicaví (puntos amarillos indican lugares de los sondeos excavados).

Close-up aerial view of the raised fields in Paicaví (yellow dots indicate test pits). 


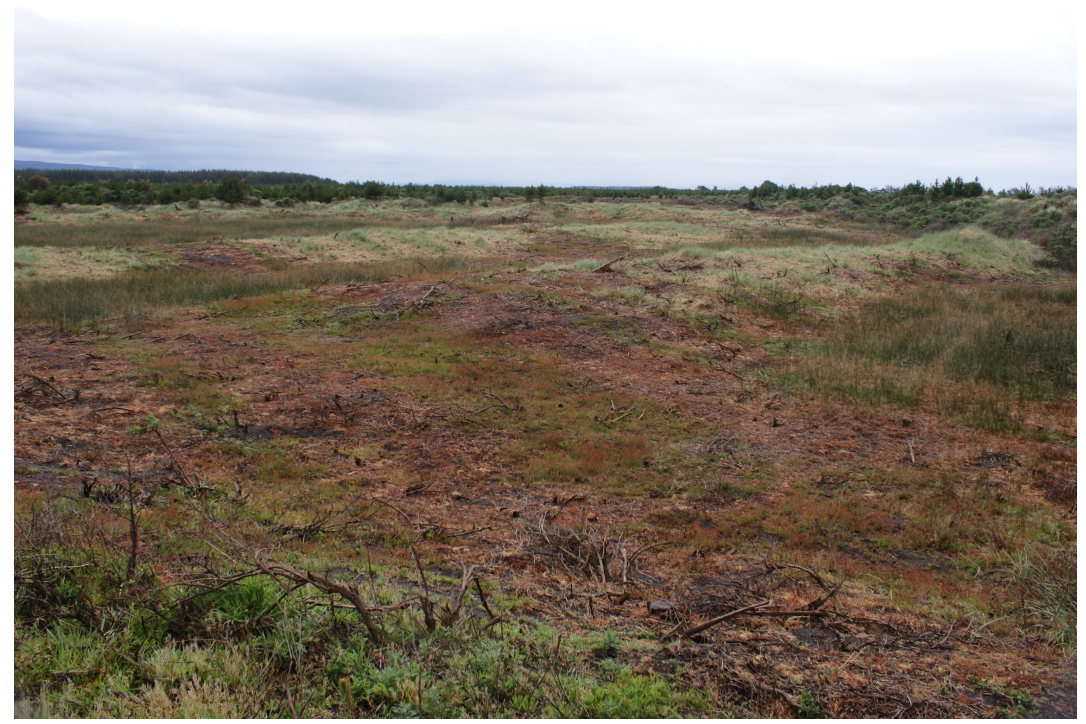

Figura 7. Vista de un sector de los camellones de Paicaví.

View of a sector of the raised fields.

sido áreas geográficas parcial y claramente modificadas por programas del Gobierno de Chile con fines de control de dunas naturales desde 1972 (Dillehay et al. 2007), la zona de Paicaví se encuentra más intacta, con ligeras modificaciones en algunos campos elevados cerca de los bordes de zonas con plantaciones de pinos (fotografías aéreas de 1962 revelan la forma original y la integridad de los campos próximos al Lago Budi, en ese momento parcialmente cubiertos por extensas formaciones de dunas).

Los campos elevados de Paicaví incorporados dentro de los límites de las plantaciones de pinos de una empresa forestal, se construyeron en una amplia franja de tierra ligeramente más baja que se encuentra entre la costa y el interior, tierras más secas, y una laguna natural localizada más hacia al este. Localizados aproximadamente a $8 \mathrm{~km}$ en dirección Este se encuentran las colinas empinadas y boscosas de la cordillera de Nahuelbuta, con pasos hacia el Valle de Purén y Lumaco. Esta ubicación fue particularmente apropiada para explotar el drenaje del Río Paicaví, el más grande en esta área de la costa. Los humedales de temporada se forman en esta zona alrededor de los campos señalados.

La existencia de canales artificiales alimentados por el Río Paicaví localizados hacia el norte y aguas subterráneas y lluvias estacionales, alimentaron los campos elevados. Los humedales al sur del delta del río fueron susceptibles de intervención humana por medio de estructuras hidráulicas artificiales, tales como pequeños embalses, diques y canales de riego. Según informantes locales algunos de estos canales son modernos o han sido modificados en tiempos modernos y fueron diseñados por los dueños de fundos locales en la época de 1960; y algunos se usan actualmente. Otros, varios de ellos, son los remanentes y testimonios de antiguos canales de drenaje. Los más modernos se pueden distinguir de los antiguos por su profundidad, anchura y longitud. Éstos últimos se presentan más pequeños y directamente asociados con fragmentos cerámicos en la superficie. Además, los canales modernos se encuentran a lo largo de los bordes exteriores de los camellones, precisamente para drenarlos. Los canales antiguos están incorporados con los campos actuales posiblemente para administrar los niveles de agua dentro de ellos ${ }^{2}$.

Las Figuras 5-7 ilustran un sistema reticulado de canales artificiales que alimenta el agua del río hacia los campos en la zona. Esta red de canales tiene varias características. La red consiste en una disposición reticular de varios canales longitudinales orientados de este a oeste, articulados por una serie de canales más pequeños (Figura 8). Se detectan otros canales orientados de norte a sur disecando este complejo de campos. Nuestro estudio preliminar no permite comprender por completo cuáles de estos canales (o todos ellos), sirven principalmente como conductos para extraer y drenar el agua del paisaje o distribuir el agua hacia los campos. Estimamos que hay por lo menos de 2,6 $\mathrm{km}$ de canales dentro de la red. El ancho de los canales adyacentes varía de 3,5 a $7 \mathrm{~m}$. La mayoría de los canales son paralelos entre sí y orientados en forma diagonal al viento, hacia el SO en dirección a la costa. En resumen, los canales y drenajes probablemente cumplieron una doble función: drenaje y distribución. Un muro de dique artificial largo de $\sim 1,1 \mathrm{~km}$ y $\sim 4 \mathrm{~m}$ de altura flanquea el 
lado oeste de los campos, los protege del océano y del avance de dunas.

Dado lo preliminar de este estudio, no hemos analizado aún detallademente las diferentes formas de canales y diques y la manera que están integrados en la red de camellones, a pesar que se presentan más o menos homogéneos en sus formas, dimensiones y funcionamiento.

Dos características geomorfológicas adicionales contribuyen al régimen hidrológico presente en esta área. Primero, el Río Paicaví fluye inmediatamente al norte de los campos, contribuyendo con el agua subterránea local a través de una profunda infiltración. En segundo lugar, debido a la topografía local el agua subterránea en su totalidad fluye de NE a SO de la llanura, cargando constantemente el acuífero de la planicie costera cercana a la superficie. El producto de estas diversas condiciones hidrológicas es que el nivel del agua subterránea en el lado sur del Río Paicaví, con frecuencia aflora en la superficie, particularmente durante los meses de invierno cuando las entradas de agua alcanzan su punto máximo. Durante este tiempo se forman charcos de agua o mallines casi a lo largo de toda la planicie costera. Durante la estación seca, el nivel freático se mantiene bastante cerca de la superficie. Sin embargo, a pesar del aspecto relativamente bien regado del costado sur del río, al menos hoy en día, el área no mantiene humedales extensos y permanentes.

La infraestructura hidráulica desarrollada para apoyar la antigua agricultura de campos elevados en el área gira en torno al drenaje adecuado de la humedad natural. Esta estrategia se ve mejor como extracción, eliminando el exceso de agua que podría evitar la agricultura sostenible. El estudio de los campos elevados lleva a considerar otro punto esencial. Los arquitectos pretéritos de los campos evidentemente apreciaron las diferencias ambientales entre las secciones de laderas con técnicas de corte y quema en las montañas de Nahuelbuta hacia el este (Cona 1930); la agricultura de llanura de inundación en los valles interiores y la agricultura de humedales y estuarios a lo largo de la costa (Dillehay et al. 2007), evidentemente respondieron a estas diferencias desarrollando estrategias alternativas de explotación de la tierra y el agua, lo cual se refleja materialmente en las características hidráulicas funcionalmente distintas de la zona del litoral costero de Paicaví.

Dentro de este sistema es pequeña la variabilidad morfológica planteada entre los campos elevados. Los campos son plataformas elevadas que van desde 1,2 a 1,8

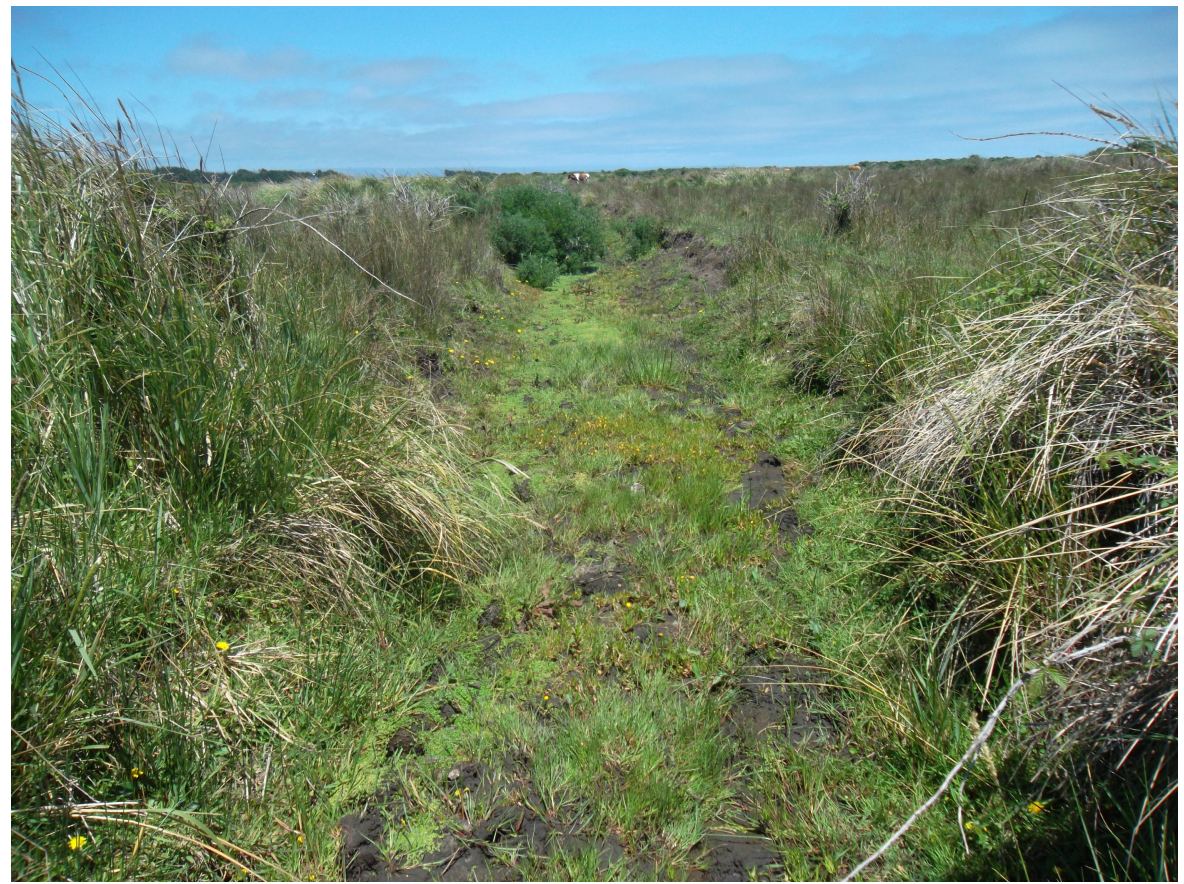

Figura 8. Canal antiguo de los camellones.

Ancient canal of the raised fields. 
$\mathrm{m}$ de alto, 8 a $10 \mathrm{~m}$ de ancho y 30 a $75 \mathrm{~m}$ de largo. Dentro de un sector dado del sistema de campo, aproximadamente entre el 30 al 60 por ciento del área corresponde a la superficie de siembra en sí. Como se mencionó anteriormente, los canales intermedios que derivan su agua de redes fluviales locales, las aguas subterráneas filtradas o aguas de las precipitaciones estacionales, ocupan la porción restante. Complementariamente, este sistema fue mejorado y regulado por estructuras hidráulicas artificiales como diques y acueductos.

La estructura interna indica que la arena de la superficie original de la tierra, evidentemente modificada durante la estación seca, fue excavada y apilada para construir las plataformas de base largas y planas, sumando dos planos sucesivos de plataformas agregadas a estas bases. La estructura interna de los campos es bastante simple y directa. Las superficies enterradas y originales de los campos elevados se encontraron aproximadamente a $30-40 \mathrm{~cm}$ por debajo del plano de referencia local y la superficie del suelo no modificada. Allí el suelo cambió de composición y tonalidades, desde arena fina, gris rojiza clara $(7.5 \mathrm{R} 7 / 1)$ a arena ligeramente grisácea rojiza (7.5YR 7/1). Las superficies enterradas no presentaban capas ricas orgánicamente, dando la impresión que probablemente algunos campos no se usaron extensivamente o quizás durante periodos de tiempo prolongados, especialmente en tiempos de paz con los españoles. La presencia de unas superficies definidas y claras de plantación única y delgada (3-5 cm de espesor dentro de capas orgánicas de $25-30 \mathrm{~cm}$ de espesor) que hemos excavado también sugiere un uso mínimo y intermitente (Figura 9, Capa 2), a pesar que se requiere mas excavaciones para probar este punto, dado que nuestra muestra es muy limitada. Excavaciones y estudios químicos en dos camellones adicionales no muestran muy claramente pisos usados. Podria ser que no toda el área de campos elevados o toda la superficie de cada uno, fue utilizada en el mismo momento.

\section{Metodología de Prospección Superficial y Excavación}

En cuanto a la prospección de superficie hemos visitado la zona bajo estudio cinco veces, registrando las dimensiones y orientaciones de los camellones, recogiendo material cultural de la superficie y excavando sondeos limitados. Nuestra prospección arqueológica no sistemática de los sitios que se encuentran fuera de la zona de camellones, registró 32 sitios habitacionales y un fortín español en los alrededores del Río Paicaví y el Lago Lanalhue. Son sitios inspecionados en superficie, salvo el fortín, donde hemos excavado varios sondeos. Varios de estos sitios son muy extensos cubriendo entre

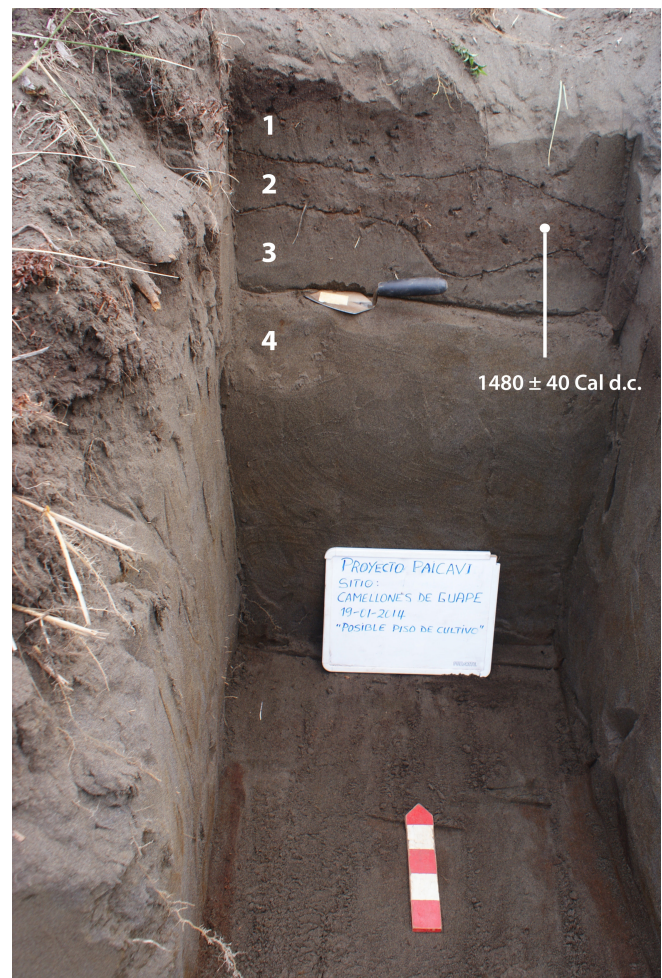

Figura 9. Sondeo o Pozo 1 excavado en Camellón 2 de Paicaví. Estrato 1 es medio orgánico y color gris rojizo claro (7.5R 7/1). Estrato 2 es más orgánico y gris rojizo (10/R 7/1). Estratos 3-4 son de arena no-orgánicos y gris medio azul (5B 6/1).

Test Pit 1 excavated in Raised fields 2 in Paicaví. Stratum 1 is partially organic and has a clear reddish grey color (7.5R 7/1). Stratum 2 is more organic and a reddish grey (10/R 7/1). Strata 3-4 are sand and non-organic material with a bluish grey color $(5 B 6 / 1)$

3 a 5 ha. Otros son más pequeños y limitados a $0,5-$ 2 ha. También en los alrededores de Cañete, Reputo y Elicura, entre 5-15 km de distancia del Río Paicaví, hemos encontrado varios montículos kuel. Todos estos sitios estan asociados con cerámicas tardías estimadas a fechar entre el periodo Prehispánico Tardío al periodo Colonial y posiblemente asociados con las actividades agrícolas en la zona de los camellones. No obstante, para asociar los camellones con estos sitios se requieren de más prospecciones y excavaciones.

La estrategia metodológica para la excavación de sondeos consistió en establecer cinco sondeos de 1,0-1,5 por 1,0 m en cinco camellones dispersos en la zona de estudio. Para seleccionar los camellones a sondear se consideraron dos aspectos básicos: (a) las características de la formación única de algunos (sean corto de dimension o forma de "L"); y (b) el posible régimen de fluviosidad de aguas al que pudo estar expuesta la superficie interna. De este modo, los sectores seleccionados para las excavaciones consideraron secciones localizadas en el costado y base 
del camellón. Las capas distinguidas fueron numeradas correlativamente del 1 al 3 ó 4, a contar de la misma superficie del camellón. La excavación fue realizada mediante procedimientos estándar (pala, espátula y brocha). Todo el material excavado fue pasado por harnero con malla de $0,5 \mathrm{~cm}$ de grosor.

Tres de los cinco sondeos (Pozos 1, 3 y 5) rindieron capas orgánicas o pisos culturales (Figura 9). Sin embargo, solo un sondeo (Pozo 1) ha producido un piso cultural claro y bien definido, identificado mediante estudios químicos. En cuanto a este piso en particular, inicialmente fue considerada una estratigrafía artificial para los primeros $25 \mathrm{~cm}$. A partir del primer nivel y considerando que se detectó la presencia de un suelo o piso cultural a los $\sim 25 \mathrm{~cm}$ de profundidad, en Pozo 1 por ejemplo, la excavación fue continuada en base a niveles naturales, detectando tanto la conformación estratigráfica del suelo y características de su composición, como indicadores y rasgos culturales presentes en sus diferentes capas. Pero, además, estableciendo niveles artificiales de control en profundidades variables cuyo objetivo fue visualizar cambios significativos en toda la excavación. El piso cultural orgánico (Camellón 2, Pozo 1, Capa 2) rindió un solo fechado de una semilla carbonizada, fragmentada de una especie no identificada 1480+40 cal DC (N DAMS-022219) (Figura 9).

Muy pocos materiales culturales se encontraron directamente en los campos agrícolas, lo cual es típico de otros campos cultivados en Sud América (Bouchard y Usselmann 2006; Gassón y Rey 2006; Kolata 2004; Plazas y Falchetti 1981). Se recuperaron algunos fragmentos de piedras, tejas españolas, litícos y varios fragmentos de cerámica, algunos de los cuales son bordes diagnósticos, por ejemplo el engobe rojo pulido de la cerámica prehispánica tardía El Vergel. La presencia de tiestos de cerámica rústica (Figura 10) y unos pocos fragmentos de bordes diagnósticos ocasionalmente con un engobe rojo, sugiere que los campos pudieran asociarse a finales del periodo El Vergel, y hasta principios del periodo hispánico, aproximadamente desde 1400 hasta el 1700 DC. Solo un fragmento cerámico no diagnóstico fue recuperado de capas excavadas de los sondeos de los camellones. También observamos pequeñas áreas abiertas entre camellones que exhibieron fragmentos de tiestos y de piedras de moler, quizás sugiriendo espacios de talleres cercanos dentro y alrededor de los campos. Se desconoce si ello refleja tareas de molienda en asociación a los campos o si se desechaban piedras de moler. Es muy probable que no

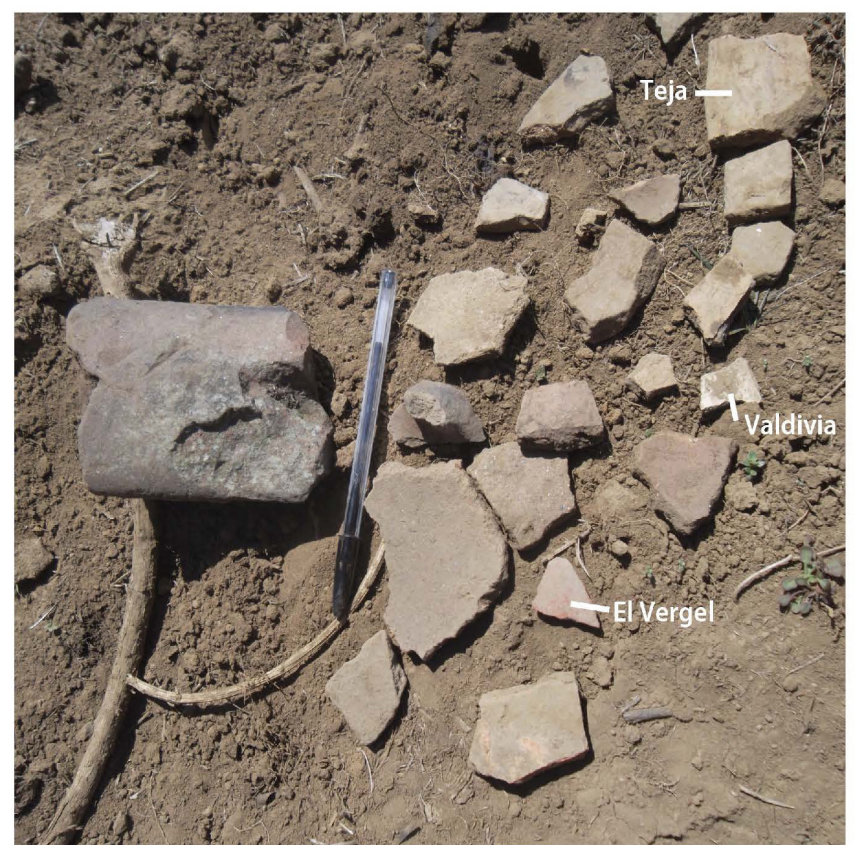

Figura 10. Tiestos de cerámica mapuche y española de por lo menos los siglos 15 a 17 encontrado en la superficie de la zona de los camellones. Nótese la piedra de moler a la izquierda y la cerámica Valdivia, El Vergel engobe rojo y la española.

Typical Mapuche and Spanish ceramic fragments dating to at least the 15th and 17 th centuries found on the surface of the raised fields. Note the grinding stone at the left and the Valdivia, El Vergel and Spanish ceramics. 
se utilizaban espacios previamente habitacionales como agrícolas, considerando que las piedras de moler recuperadas en dicho sector son pocas y aisladas. Este es un patrón que también observamos en los campos elevados del Lago Budi en Puerto Saavedra.

El análisis químico de muestras de suelo de las superficies enterradas y excavadas en las plataformas (seis litros en total de los cinco testados), realizado por el Laboratorio de Suelo de la Universidad de Kentucky, EEUU, apoya la idea que estas superficies representan intervención humana. El alto valor total de fosfato existente en los campos, en comparación con las áreas arenosas naturales y sin campos elevados, indica sedimentos antropogénicos (Tabla 1). Además, a pesar que los estudios de fitolitos y granos de almidón de muestras de sedimentos tomadas de la subsuperficie de un camellón excavado, no entregaron trazas claras debido a que las muestras estaban muy destruidas por los movimientos de arena sin concentraciones diagnósticas suficientes para identificar (ScottCummings 2017), es possible que los campos estuvieran enfocados a producir mayormente papas y frijoles. Actualmente, las familias mapuche que viven alrededor mantienen similares cultivos, además de maíz; y, relatan que en el pasado los ancianos cultivaban estos productos en los campos.

Tabla 1. Fraccionamiento de muestra de sedimentos de fosfato de camellón y no-camellón

Fractioning of phosphate in samples from both camellones and non-camellones sediments.

\begin{tabular}{lclc}
\hline $\mathrm{N}^{\circ}$. Muestra & $\begin{array}{c}\text { Profundidad } \\
\mathrm{cm}\end{array}$ & Contexto & $\begin{array}{c}\text { Fosfato en } \\
\text { fracciones por m }\end{array}$ \\
\hline $\begin{array}{l}\text { 1. Camellón 2 } \\
\text { Pozo 1 }\end{array}$ & $20-25$ & $\begin{array}{l}\text { Estrato } \\
\text { agrícola N }\end{array}$ & 209,4 \\
$\begin{array}{l}\text { 2. Camellón 2 } \\
\text { Pozo 1 }\end{array}$ & $25-38$ & $\begin{array}{l}\text { Estrato } \\
\text { agrícola N }\end{array}$ & 143,7 \\
$\begin{array}{l}\text { 3. Estrato } \\
\text { no-camellón }\end{array}$ & $28-34$ & No agrícola & 94,5 \\
$\begin{array}{l}\text { 4. Estrato } \\
\text { no-camellón }\end{array}$ & $30-40$ & No agrícola & 112,0 \\
\hline
\end{tabular}

* Análisis realizado por el Soil Chemistry Laboratory, University of Kentucky, EEUU.

\section{Conclusión}

Paicaví es un territorio mapuche costero muy citado a lo largo de la historia desde la llegada de los españoles, por haber sido parte fundamental de la "provincia" de Tucapel desde la segunda mitad del siglo XVI hasta, a lo menos, la primera mitad del siglo XVII. Tucapel fue uno de los "graneros" de la conquista española y una fuente importante de mano de obra, elementos sin los cuales quizás no se podría haber sustentado la empresa conquistadora hispana del siglo XVI. Sus buenas condiciones para los cultivos y la ganadería, señaladas en todas las épocas, hicieron de sus planicies costeras, y en particular de Paicaví, un territorio poblado y con una actividad agro-pastoril intensa.

Su carácter de posible "reserva" alimentaria y demográfica para españoles y mapuche, debió ser apreciada en tiempos de guerra y sobre todo al principio de la presencia hispana en la zona. La conquista española seguramente provocó la intensificación de las prácticas agrícolas, ya fueran intermitentes, durante momentos de conflicto y repliegue o de manera más permanente. No lo sabemos aún. También, posiblemente, en los años en que estuvo presente el fuerte español en el Río Paicaví, los campos elevados pudieron servir para aprovisionar a los soldados españoles.

En base a lo anteriormente expuesto podemos suponer que las terrazas agrícolas existentes al sur del Río Paicaví fueron explotadas durante el periodo Prehispánico tardío y, con mayor seguridad, en el periodo Colonial Temprano, desde mediados del siglo XVI en adelante, pudiendo ser controladas, en ciertos momentos, por los españoles de la ciudad de Cañete (1557-1598) y, posteriormente, por los del fuerte y misión de Tucapel (siglo XVII). Con mayor probabilidad, estos campos elevados, debieron ser explotados en los periodos de existencia del vecino fuerte de Paicaví (1605-1612; 1641-1646; 1668-fines del siglo XVII). Esta estimación cronológica está basada en un único fechado de radiocarbono que salió de Pozo 1 (1480 cal DC), en la cerámica diagnóstica encontrada dispersa en los campos de Paicaví y en las informaciones indirectas de la documentación histórica. Este fechado corresponde con la edad estimativa de los camellones en la zona del Lago Budi (Dillehay et al. 2007) a igualmente del periodo Prehispánico tardío (Dillehay et al. 2007).

La gran fertilidad que al parecer poseían las tierras localizados al norte del Río Paicaví, explican quizás el hecho que allí no fuera necesario construir sistemas de terrazas y que, siendo las poblaciones indígenas independientes obligadas a desplazarse al sur de dicho cauce por la presencia española, hayan encontrado en el sistema de terrazas una buena alternativa productiva para un territorio que requería soportar, desde ese momento, una mayor presión demográfica. Otra razón podría ser que las tierras del lado sur del río, por ser a terrenos más bajos y húmedos requirieran prioritariamente utilizar la técnica de campo elevado para una buena producción agrícola.

La canalización fluvial, la modificación general de la tierra, los diques, los canales y las calzadas, sumado a la presencia de una población humana bastante densa integraron funcionalmente el esfuerzo sostenido de Paicaví para proporcionar una sobreproducción agrícola que pudo haber sido aportada a quienes estaban en el frente de guerra, por ejemplo a los combatientes del Valle de Purén. El paisaje del lado sur del Río Paicavíse puede entender mejor si se piensa como una obra 
hidráulica construida estratégica y organizadamente por un colectivo de grandes proporciones como lo fue el denominado Estado de Arauco en el que convergían grandes alianzas territoriales de los valles nahuelbutanos. El esfuerzo laboral invertido en dar forma a la tierra evidentemente significó que la mano de obra fue extraída de varios asentamientos en el área de Tucapel, pero particularmente desde Paicaví.

La agricultura probablemente no se extendió en la Araucanía hasta un poco antes de 600-1000 DC. Aunque tenemos datos arqueológicos mínimos para respaldar cualquier proposición sobre el momento de los orígenes de la agricultura y la agricultura de campos elevados en particular, se requerirían investigaciones arqueológicas adicionales para verificar esta hipótesis. El enfoque cronológico propuesto para la agricultura de campos elevados en la costa entre Arauco y el Río Tolten, la sitúa preliminarmente en algún momento antes o después de 1300-1500 DC, como lo sugieren los dos fechados de radiocarbono y los fragmentos cerámicos diagnósticos de los campos del Lago Budi (Dillehay et al. 2007) y ahora de Paicaví. Como se sugirió anteriormente, este periodo se correlaciona con importantes cambios paleo-ambientales y culturales (p.ej., migraciones de poblaciones y difusión de ideas tecnológicas) que tienen lugar en los Andes centrales y centro-sur (Dillehay et al. 2007), lo que probablemente se relaciona directa o indirectamente con la aparición de la agricultura de campos elevados en la costa de La Araucanía.

La economía prehispánica de la Araucanía aparentemente giraba en torno a varios sistemas de producción diferentes e interrelacionados: varios tipos de tala y quema, humedales y agricultura en campos elevados, tal vez pastoreo de camélidos, recolección y pesca de agua dulce y marina. Cada uno de estos sistemas estaba asociado con zonas ambientales particulares y la mayoría de las poblaciones locales probablemente dependían de combinaciones de varias estrategias y formas distintas de asentamiento y organización humana. Podría decirse que una de las manifestaciones con mayor grado de planificación y movilización de labor humana fue la agricultura de campos elevados, junto con una infraestructura de apoyo de tecnología hidráulica: diques, acopios y áreas de talleres.

La historia de la construcción de campos elevados es, en cierto sentido, emblemática en la historia más amplia de los proto-mapuche para épocas prehispánicas tardías y para el periodo Colonial Inicial. El surgimiento de este tipo de agricultura recapitula la trayectoria del desarrollo de un complejo sistema polifacético en la Araucanía que también involucraba sociedades de nivel de "cacicazgos" principales, de construcción de montículos y, en última instancia, de la resistencia política intermitente y exitosa ante el español y luego ante el Estado chileno. Una base fundamental de poder para las poblaciones mapuche prehispánicas y coloniales, especialmente en el área del territorio nahuelbutano, fue la producción sostenible de alimentos en forma de agricultura, pesca, etc. Estas estrategias de producción respaldaron el esfuerzo de guerra intermitente contra los extranjeros desde mediados del siglo XVI hasta fines del siglo XIX y la construcción de paisajes sagrados y poblaciones nucleadas en algunas áreas (Dillehay 2007). Un paso hacia una mejor comprensión de estos desarrollos requiere aumentar las investigaciones de carácter interdisciplinario sobre las complejas relaciones que sustentaron la organización de la producción de alimentos para estas poblaciones. También, se podría saber mejor si la construcción, la mantención y la explotación de los camellones fueron obras de nivel local o de nivel regional, pero se necesitan mayores evidencias históricas y arqueológicas.

Podemos poner en paralelo el desarrollo de los camellones con la evolución socio-económica y sociopolítica mapuche. Sería muy atrevido pensar que la presencia de kuel y camellones implica la existencia de un sistema de poder complejo como única fuerza política capaz de organizar la construcción de kuel y camellones (Dillehay 2007, 2014). Al mismo tiempo, no se puede deducir de forma "automática" que los líderes mapuche hayan desarrollado este sistema de agricultura intensiva para captar los excedentes de la producción agrícola para su propio y único beneficio, es decir para reforzar mayormente el poderque ejercían sobre sus comunidades. En consecuencia, queda abierta la posibilidad de sugerir líneas alternativas y/o complementarias de explicación para el surgimiento de este fenómeno.

Finalmente, no entendemos bien el origen de los camellones en la zona. Es más probable que fueran introducidos por influencias del norte de Chile o Bolivia donde se las encuentran en tiempos prehispánicos. Hasta ahora, no hay evidencia de estas obras en los valles nortinos y centrales de Chile, probablemente porque hay pocos ríos grandes y estuarios extensos en la costa. También, podría ser que la guerra con los españoles presionó a los mapuche del sur a desarrollar este tipo de cultivo y a intensificar las prácticas agrícolas, particularmente en el área de Paicaví.

Agradecimientos: Agradecemos a los mapuche y no mapuche que nos dieron permiso para entrar en sus terrenos y realizar este proyecto, al Consejo de Monumentos Nacionales por darnos permiso para trabajar en la zona. Este proyecto fue financiado por la National Science Foundation y la National Geographic Society de EEUU. Igualmente ha concurrido a su financiamiento la Comisión Nacional de Investigación Científica y Técnológica de Chile (CONICYT) a través de su Programa FONDECYT: Proyecto Fondecyt Regular n`1170551 "Tras la ruta del oro. Los habitantes de La Araucanía frente a la ocupación española del siglo XVI, recepción, adaptación y resistencia". También agradecemos a los evaluadores del manuscrito. 


\section{Referencias Citadas}

Bengoa, J. 2003. Historia de los Antiguos Mapuches del Sur: Desde Antes de la Llegada de los Españoles hasta las Paces de Quilin; Siglos XVI y XVII. Catalonia, Santiago.

Bouchard, J.F. y P. Vsselmann 2003. Trois Millénaires de Civilisation entre Colombie et Equateur, la Région Tumaco La Tolita. CNRS Editions, Paris.

Broadbent, S.M. 1968. A Prehistoric Field System in Chibcha Territory, Colombia. Nawpa Pacha 6:135-47.

Chuffa, D. 2007. Cartas y Memorias del Vice-Prefecto de misiones fr. Diego Chuffa (1842-1854). Compilación, transcripción y presentación de André Menard y Rolf Foerster. Publicaciones del Archivo Franciscano, n ${ }^{\circ}$ 98, Santiago.

Cona, P. 1930. Vida y Costumbres de los Indígenas Araucanos en la Segunda Mitad del Siglo XIX. Editorial Universitaria, Santiago.

Denevan, W.M. 1963. Additional cornments on the earthworks of Mojos in Northeastern Bolivia. American Antiquity 28:54045.

Denevan, W.M. 2001. Cultivated landscapes of Native Amazonia and the Andes. Oxford University Press, Oxford.

Denevan, W.M. y B.L. Turner II 1974. Forms, functions and associations of raised fields in the Old World tropics. Journal of Tropical Geography 39:24-33.

Dillehay, T.D. 1990. Araucanía, Presente y Pasado. Editorial Andrés Bello, Santiago.

Dillehay, T.D. 2007. Monuments, empires, and resistance: the Araucanian polity and ritual narratives, Cambridge University Press, Cambridge.

Dillehay, T.D. 2010. Late Prehispanic and Hispanic Ceramics in the Purén, Lumaco, and Liucura Valleys, Araucania, Chile. Vanderbilt University, Nashville.

Dillehay, T.D. 2014. Preliminary report on the archaeology of Río Paicaví, Chile. Report submitted to the National Science Foundation, Washington D.C.

Dillehay, T.D. 2017. La Organización Política Temprana: Materialidad y Patriarcado Andino. Pehuen Imprenta, Santiago, Chile.

Dillehay, T.D., M. Pino, R. Bonzani, C. Silva y C. Le Quesne 2007. Cultivated wetlands and emerging complexity in south-central Chile and long distance effects of climate change. Antiquity 81 (314):949-960.

Dillehay, T.D. y J. Saavedra 2003. Interacción humana y ambiente: el desarrollo de Kuel en Purén-Lumaco (Región de la Araucania). Revista Austral de Ciencias Sociales 7:17-28.

Dillehay, T.D. y J. Saavedra 2010. Los Valles de Purén-Lumaco y Liucura, Chile: Arqueología e Historia Cultural. Vanderbilt University, Nashville.

Dillehay, T.D. y J.M. Zavala 2013. Compromised Landscapes: The Proto-Panoptic Politics of Colonial Araucanian and Spanish Parlamentos. Colonial Latin American Review 22:319-343.

Domeyko, I. 1846. Araucanía i sus Habitantes. Recuerdos de un Viaje Hecho en las Provincias Meridionales de Chile, en los Meses de Enero i Febrero de 1845. Imprenta Chilena, Santiago.
Ercilla y Zúñiga, A.D. 1575. La Araucana. Casas de Domingo de Portonarijs, Salamanca.

Erickson, C.C. 1995. Archaeological Methods for the Study of Ancient Landscapes of the Llanos de Mojos in the Bolivian Amazon. En Archaeology in the Lowland American Tropics: Current Analytical Methods and Applications, editado por P.W. Stahl, pp. 66-95. Cambridge University Press, Cambridge.

Fitzroy, R. 1835. South America, West Coast: Sheet VI, Chile: Tucapel Point to Point Lora. Hydrographic Office of the Admiral, London.

Gassón, R. y Rey Juan Carlos 2006. Cacicazgos cíclicos e intensificaci6n agrícola en los Llanos Occidentales de Venezuela. En Agricultura Ancestral Camellones y Albarradas, editado por F.Valdez, pp. 141-158. Editorial Abya-Yala, Quito

Góngora Marmolejo, A. de 1862 [1575]. Historia de Chile Desde su Descubrimiento hasta el Año de 1575. Colección de Historiadores de Chile (CHCh), Tomo 2. Imprenta del Ferrocarril, Santiago.

Groot, A.M. 1992. Una Secuencia Cultural entre 8500 y 3000 años Antes del Presente. Fundación de Investigaciones Arqueológicas Nacionales. Banco de la República, Bogotá.

Guevara, T. 1908. Psicología del Pueblo Araucano. Editorial Universitaria, Santiago.

Iriarte, J., B. Glaser, J. Watling, A. Wainwright, J.J. Birk, D. Renard, S. Rostain y D. McKey 2010. Holocene Neotropical agricultural landscapes: Phytolith and stable carbon isotope analysis of raised fields from French Guianan coastal savannahs. Journal of Archaeological Science 37 (12):2984-2994.

Kolata, A. 2003. Tiwanaku and Its Hinterland: Archaeology and Paleoecology of an Andean Civilization. Volume 2. Urban and Rural Archaeology. Smithsonian Institution Press, Washington D.C.

Mariño de Lobera, P. 1960 [1580]. Crónica del Reino de Chile, Escrita por el Capitán Dn. Pedro Mariño de Lovera dirijida al Exmo. Señor Don García Hurtado de Mendoza, Marques de Cañete, Vice-rei y Capitan Jeneral de los Reinos del Perú e Chile. Reducida a Nuevo Método, y Estilo por el Padre Bartolomé de Escobar, de la Compañía de Jesus. Colección de Historiadores de Chile (CHCh), Tomo VI. Imprenta del Ferrocarril, Santiago.

Parsons, J.J. 1966. Los campos de cultivos pre-hispánicos del bajo San Jorge. Revista de la Academia Colombiana de Ciencias Exactas, Físicas y Naturales 12 (48):449458.

Parsons, J.J. 1969. Ridged fields in the Rio Guayas Valley, Ecuador. American Antiquity. 34:76-80.

Olaverría, M. 1852 [1594]. Informe de Don Miguel de Olaverría sobre el Reyno de Chile, sus Indios y sus Guerras 1594. En Claudio Gay, Historia Física y Política de Chile, Documentos, vol. 2., pp. 13-54. Casa del Autor, París.

Plazas, C.y A.M.Falchettide Saenz 1981.Asentamientos Prehispanicos en el Bajo Río San Jorge. Banco de la República, Bogotá.

Pozorski, T., S. Pozorski, C.J. Mackey y A.M.U. Klymyshyn 1983. Pre-Hispanic Ridged Fields of the Casma Valley, Peru. Geographical Review 73:407-416.

Rosales, D. de 1878. Historia General de el Reyno de Chile, Flandes Indiano. Edición de Benjamín Vicuña Mackenna. Imprenta del Mercurio (tomo I y II), Valparaíso. 
Rostain, S. 2008. Agricultural Earthworks on the French Guiana Coast. En Handbook of South American Archaeology, editado por H. Silverman y W.H. Isbell, pp. 217-233. Springer, New York.

Siemens, A.H. 1989. Tierra Configurada. Investigaciones de los Vestigios de Agricultura Precolombina en Tierras Inundables Costeras desde el Norte de Veracruz hasta Belice. Consejo Nacional para la Cultura y las Artes, México D.F.

Valdivia, P. de 1955 [1555]. Cartas al Emperador Carlos V. Francisco. Editado por Esteve Barba, Crónicas del Reino de Chile, Madrid.

Vivar, J.D. 1966 [1558]. Cronica y Relacion Copiosa y Verdadera de los Reinos de Chile. Fondo Historico y Bibliográfico José Toribio Medina, Santiago.

Zavala, J.M. 2008. Los Mapuches del Siglo XVIII: Dinámica Interétnica y Estrategias de Resistencia. Editorial Universidad Bolivariana, Santiago.

Zavala, J.M. 2015. Los Parlamentos Hispano-Mapuches, 1593-1803: Textos Fundamentales. Universidad Católica de Temuco, Temuco.

Zavala, J.M. y T.D. Dillehay 2010. El "Estado de Arauco" frente a la conquista española estructuración sociopolítica y ritual de los araucanomapuches en los valles Nahuelbutanos durante los siglos XVI y XVII. Chungara Revista de Antropología Chilena 42 (2):433-450.
Zavala, J.M., T.D. Dillehay, G. Payàs y F. Le Bonniec 2015. Los parlamentos hispano-mapuches como espacios de reconocimiento del otro enemigo: huellas históricas, lingüísticas y territoriales. En Traducción y Representación del Conflicto, editado por I. Alonso Araguás, A.Páez Rodríguez y M. Samaniego Sastre, pp. 35-48. Ediciones de la Universidad de Salamanca, Salamanca.

Zavala, J. M., T.D. Dillehay, G. Payàs y F.J. Medianero 2018. El oro de la Araucanía como articulador de las relaciones interétnicas en el siglo XVI: certezas e interrogantes. XXI Congreso Nacional de Arqueología Chilena, 3-7 de diciembre 2018. Universidad Alberto Hurtado, Santiago. En prensa.

Zucchi, A. y W.M. Denevan 1979. Campos elevados e historia cultural prehispánica en los Llanos Occidentales de Venezuela. Montalban 9:565-736.

\section{Archivos}

Archivo General de Indias, Sevilla [AGI]

Audiencia de Chile [Ch.)] legajos 18, 30 y 31.

Archivo Nacional Histórico de Chile [ANHCh]

Ministerio de Marina [MM], vol. 145

Manuscritos Vicuña Mackenna [MVM], vols, 272 y 273.

\section{Notas}

\footnotetext{
${ }^{1}$ No sabemos si este término también se refiere a otras grandes estructuras públicas mapuche como los montículos artificiales (kuel) los canales y caminos. El investigador chileno Tomás Guevara menciona que la palabra mapuche para camellones es reduin (Guevara 1908:88).
}

${ }^{2}$ Informantes locales refieren que sus abuelos hablaron de antiguos camellones y canales que habían sido utilizados por los mapuche y que los fundos modernos intentaron sin éxito cultivar la tierra para el pastoreo de animales construyendo dos canales más grandes para drenarla 
